\title{
Relationship Between Demographic Factors and Religious Orientation and the Reproductive Behavior of Employed Women in Tehran
}

\author{
Marzieh Saei Ghare naz ${ }^{1}$, Giti Ozgoli², Fahimeh Hajizadeh ${ }^{2}$, Zohre Sheikhan ${ }^{2}$, Malihe Nasiri $^{3}$, Sharareh \\ Jannesari $^{3}$
}

\begin{abstract}
Objectives: Changes in the fertility rate over the past 3 decades in Iran warn us of the reduced rate of the fertility and negative population growth and fear of population aging in coming years. Given the nationwide important role of the fertility behavior in the country's economic and social growth, this study aimed to determine the relationship between the demographic factors and the religious orientation and the reproductive behavior of women working in Tehran city, Iran.

Materials and Methods: In this cross-sectional study, a total of 200 women working in the healthcare centers affiliated to Shahid Beheshti University of Medical Sciences and the selected education centers of Tehran and those who met the inclusion criteria, were selected using convenient sampling method. Moreover, the data were collected using reproductive behavior and religious attitude questionnaires developed by Golriz and Baraheni and the demographic questionnaire.

Results: The findings showed that a total of $63.5 \%$ and $36.5 \%$ of women were working in the healthcare centers and education centers, respectively. There was a meaningful and reverse correlation between the reproductive behavior and the religious orientation in the present study $(r=-0.23, P>0.05)$. There was also a statistically significant difference between the place of employment and the reproductive behavior score $(P>0.05)$, in such a way that the average score for the reproductive behavior of women working in the healthcare centers was higher than that of women working in the education centers.

Conclusion: The results of the present study indicated that the religious orientation affects the working women's reproductive behavior. Thus, providing the perfect conditions to promote religious beliefs can play a prominent role in balancing individuals' reproductive behavior.

Keywords: Employment, Religion, Reproductive behavior, Women
\end{abstract}

\section{Introduction}

Fertility is an important public-social phenomenon, the rate of which is variable in different populations (1). Iran has also experienced wide demographic changes in parallel with the developments in world population in recent years. Over the past 3 decades, the fertility rate has been declined dramatically in Iran, as a result of which Iran has joined countries with a fertility rate equal or below the replacement level (2). The results of censuses and national statistics show that the total fertility rate was reached 1.6 children per woman in 2011 compared with about 7.7 children per woman in 1966 (3). According to the World Bank, population growth rate in Iran will be declined to less than $1 \%$ in 2025 . World Bank had also estimated that Iran's population growth would be reduced to $1.59 \%$ between 2010 and 2014. In addition, the population growth will be reduced to $1.32 \%$ and $1.13 \%$ between the years 2015 and 2019, and 2020 and 2024, respectively (4). This uncommon fertility decline in Iran has been amazing internationally (5).

Reproductive behavior is influenced by various factors in any society. The factors affecting the reproductive behavior can be studied in both macro and micro levels. At the macro level, the underlying factors including the impact of environmental, social, political, and cultural factors on the fertility behavior are studied; while at the micro level, the effect of psychological and mental factors such as motivation, aspirations and attitudes of individuals towards the reproductive behavior is considered (6). Over time, these changes led women to go outside of the environment of the home, and make changes in the traditional work pattern governing the society. Moreover, high number of women was attracted to the occupational system of the society as a result of the changes (7). In the past, most women were deprived of job opportunities due to their housekeeping roles and were not entitled to the education and employment opportunities compared with men. In such circumstances, women were not exposed to conflicting expectations and high rates of fertility were normal. Today, women have the same access to these opportunities as men in many countries. However, in order to benefit more from these opportunities, they have

Received 23 November 2016, Accepted 13 March 2017, Available online 20 March 2017

${ }^{1}$ Student Research Committee, School of Nursing \& Midwifery, Shahid Beheshti University of Medical Sciences, Tehran, Iran. ${ }^{2}$ Center for the Study of Religion and Health, Shahid Beheshti University of Medical Sciences, Tehran, Iran. ${ }^{3}$ Department of Midwifery \& Reproductive Health, School of Nursing \& Midwifery Shahid Beheshti University of Medical Sciences, Tehran, Iran.

*Corresponding Author: Giti Ozgoli, Tel: +982188202512, Email: gozgoli@gmail.com 
to ignore or reduce their fertility rate (8).

In a study, Musaee et al concluded that there was a bilateral and inverse relationship between women's employment and the fertility rate in Iran, to such a degree that more fertility rates could lead to a reduction in the female labor force and thus reduce their participation rate in the labor force. On the other hand, as women's employment rate is increased, the fertility rate is decreased (9). One of the cultural factors influencing the tendency of childbearing is the religious orientation of individuals. Religion dictates instructions for life as well as referring to a system of beliefs, attitudes and actions, which is shared among the members of that religious group; thus this religious orientation affects their reproductive behavior (10).

Religiosity is known as the important components of well-being (11). Religion can have direct and indirect effects on the demographic behavior of individuals (12). It organizes collective spiritual experiences of a group of people within a system of beliefs and practices. The religiosity refers to the degree of participation in the adoption of beliefs and practices of an organized religion as well as the level of adoption of those beliefs and practices (13). Strong religious beliefs strengthen values and norms of a group by adding a sacred dimension to everyday life in a society (14). Religious beliefs play a role in the formation of fertility strategies (15). Goldscheider points to the importance of the correlation between the religious affiliation and fertility and uses the expression "specialized theology." He also believes that different fertility rates of different religious groups imply their different religious teachings (16). In a study by Mahmudian and Nobakht, religion explained $0.38 \%$ of changes related to women's reproductive behavior (17). Hayford and Morgan also highlighted that the actual fertility rate and the childbearing tendency in women who maintain that religion is very important in everyday life was more than those who believe that religion is not important or is of little importance (18). Religion continues to be an important determinant of the fertility and family formation patterns in Britain, France and the Netherlands (19).

These days, the fertility decline, risk of negative population growth, and fear of an ageing society in coming years are ubiquitously talked about in scientific circles and the media. Even media encourage families to childbearing. It should be noted that population policies should be evolutionarily designed according to the population structure in each country and always be evaluated. These assessments sometimes indicate that new policies must be developed and implemented. Sustainable and comprehensive population policies cannot be designed without deep and careful study and understanding population issues (20). Therefore, due to changes in the fertility rate over the past 3 decades in Iran, it is necessary to identify factors affecting behavior, ideals, and childbearing tendency of women and establish them as the basis for population policy. On the other hand, the relationship between the religious orientation and the women's participation in the labor market is of particular importance as a key factor affecting the fertility rate and the economic growth in current situation of the society. Therefore, this study aimed to determine the relationship between demographic factors as well as the religious orientation and the reproductive behavior among working women in Tehran.

\section{Materials and Methods}

This cross-sectional study was conducted on 200 women working in the healthcare centers affiliated to Shahid Beheshti University of Medical Sciences and the selected education centers in Tehran in 2015. Inclusion criteria were: Iranian nationality, living in Tehran, women of childbearing age, working in health centers affiliated to Shahid Beheshti University of Medical Sciences and practitioners in education centers in Tehran, and satisfaction with participating in the study.

Exclusion criteria were: women's lack of satisfaction with completing the questionnaire or incomplete questionnaires. A sample size of 200 was calculated using the following formula with respect to the sample loss:

$\mathrm{n}=\left[\frac{\left(\mathrm{z}_{1-\frac{\mathrm{a}}{2}}+\mathrm{z}_{\mathrm{b} / 2}\right)}{0.5 \times \ln [(1+\mathrm{r}) /(1-\mathrm{r})]}\right]^{2}+3$

In this study, non-random convenience sampling was used. Data collection tools included a demographic questionnaire to evaluate demographic characteristics, a reproductive behavior questionnaire, and a religious attitude questionnaire. The questionnaires were defined as follows:

"Demographic Characteristics Questionnaire": The questionnaire contains information on age, occupation and place of birth, native language, type of employment and religion.

"Reproductive Behavior Questionnaire": In this questionnaire, the reproductive behavior including the age at the time of marriage, number of children, childbearing tendency, use of contraception methods, proper pregnancy spacing, ideal number of children at the time of marriage, ideal number of children at the time of the study and gender preference are measured. Questionnaire scoring is on the basis that 8 and 16 scores, respectively shows the worst and the best reproductive behaviors (21).

"Religious Attitude Questionnaire", on which psychometric evaluation was performed and has been developed in Iran, is applicable in the Iranian society and contains 25 questions and 2 items (22). Scores are classified as 0 -100 scale based on 4 scales, including excellent, good, average, and poor religious attitudes, respectively with score ranges of 76-100, 51-75, 26-50, and equal or lower than 25. Moreover, the validity of the questionnaire was obtained 0.8\% using Allport-Vernon-Lindzey test (23). The questionnaire was re-evaluated in recent years; the reliability and validity of the questionnaire were obtained 
as $0.63 \%$ and $0.248 \%$, respectively using Spearman-Brown method, which demonstrates the trustworthy nature of the questionnaire results. The retest reliability method was used to determine the reliability of the questionnaire.

The questionnaire was given to 10 women eligible for the study within 2 weeks and the test reliability coefficient was measured by calculating the correlation coefficient between scores. After being collected, the data were analyzed using SPSS 17.0. Descriptive statistics, Pearson correlation coefficient and Spearman correlation were used to describe the data, to investigate the quantitative relationship between data, and to study the qualitative relationship between data. A significance level of $0.5 \%$ was considered while performing the test.

\section{Results}

A total of 200 women who were working in health centers affiliated to Shahid Beheshti University of Medical Sciences and selected education centers in Tehran participated in this study. Mean (SD) age of the women participating in the study was 36.52 (7.9) years. A total of $63.5 \%$ and $36.5 \%$ of women were working in the healthcare centers and education centers, respectively. Moreover, permanent, fixed-term (5-year), fixed-term (1-year), and daily paid employees, respectively accounted for $0.5 \%, 51.5 \%, 41.5 \%$ and $2 \%$ of the participants. A total of $99.5 \%$ and $0.5 \%$ of the subjects were Shia and Sunni, respectively. A total of $78 \%$ and $22 \%$ of the participants spoke Farsi and nonFarsi languages, respectively. A total of $90.5 \%$ and $9.5 \%$ of women were born in cities and villages, respectively. In this study, the mean (SD) age of the marriage was 24.35 (4.32).

Table 1 shows different aspects of the reproductive behavior of the subjects. The mean (SD) scores of religious orientation of women working in the healthcare centers and education centers were $76.75 \%$ (11.76) and $79.54 \%$ (8.6), respectively. The independent $t$ test results showed a statistically significant difference between the place

Table 1. Characteristics of Reproductive Behavior of the Study Participants

\begin{tabular}{lc}
\hline Variables & $24.35(4.32)$ \\
\hline Marriage age, mean (SD) & $1.23(0.86)$ \\
Number of children, mean (SD) & $2.21(0.97)$ \\
Ideal number of children at the time of marriage, mean & \\
(SD) & $2.04(0.8)$ \\
Ideal number of children at the time of study, mean (SD) & $3.99(2.46)$ \\
Pregnancy spacing, mean (SD) & $187(93.5)$ \\
Gender preference, No. (\%) & $13(6.5)$ \\
$\quad$ Not differs & $156(78)$ \\
Boy & $44(22)$ \\
Use of contraception, No. (\%) & \\
Yes & \\
No & \\
Childbearing tendency, No. (\%) & $158(79)$ \\
$\quad$ Yes & \\
No &
\end{tabular}

of employment and the reproductive behavior score $(P>0.5)$, as the average score of women working in the healthcare centers was more than that of women working in the education centers. However, there was no significant difference between the first language and the place of birth $(P<0.05)$. Based on the analysis of variance (ANOVA) test, there was no statistically significant difference between the age and the employment type $(P<0.05$; Table 2$)$.

The mean (SD) scores of the reproductive behavior and the religious orientation are shown in Table 3. Based on these scores, the Pearson correlation coefficient showed a statistically significant relationship between the fertility behavior and the religious orientation $(r=-23 \%, P>0.5)$.

\section{Discussion}

The findings showed that the means (SD) of the reproductive behavior and the religious orientation of subjects were $11.13 \%(1.18 \%)$ and $77.7 \%(1.87 \%)$, respectively. Moreover, based on the results of this study, there was an inverse significant correlation between the religious orientation and the reproductive behavior, in such a way that with an increase in the religious orientation toward excellent end, the reproductive behavior was reduced and shifted toward excellent reproductive behavior.

In the present study, there was a statistically significant difference between the place of employment and the score obtained for the reproductive behavior in terms of the demographic characteristics to such an extent that the average score obtained for the reproductive behavior of women employed in the healthcare centers was higher than that obtained for those working in the education centers. This finding suggests that women employed in the health centers have worse reproductive behavior than women working in the education centers. In terms of other demographic variables, there was no statistically significant difference in the reproductive behavior. The findings of the study by Shiri et al showed that women working in education centers had more organized social relations and preferred to have fewer children in any given times (24). In a study, Moshfeg and Eshgi-Gharib displayed that there was a statistically significant difference between the child valuation in different groups of working women (women employed in the Ministry of Health and the educational organization) (6).

In a study, Hosseini and Hosseini found that there was no significant relationship between women's religion and their reproductive behavior; however, there was a direct and significant relationship between the ideal number of children and jobs of women with the reproductive rate (25). In line with the present study, some studies have also emphasized the positive and meaningful effect of religious beliefs on women's childbearing and reproductive behavior (26-28). In an empirical study, Lund demonstrated that introducing and developing the religious concepts in people would increase the childbearing rate (29). Another study in Pakistan explained that the reproductive behavior 
Table 2. Baseline Demographic Characteristics of the Study Participants

\begin{tabular}{|c|c|c|c|}
\hline Variables & & Reproductive Behavior Score & $P$ Value \\
\hline \multirow{4}{*}{ Age } & $15-25$ & $11.38(1.38)$ & \multirow{4}{*}{$\begin{array}{l}F=0.4 \\
P=0.7\end{array}$} \\
\hline & $26-35$ & $11.14(1.34)$ & \\
\hline & $36-45$ & $11.10(1,10)$ & \\
\hline & $>45$ & $11.09(0.86)$ & \\
\hline \multirow{2}{*}{ Place of employment } & Education center & 10.38(0.88) & \multirow{2}{*}{$\begin{array}{l}\mathrm{F}=7.57 \\
P=0.007\end{array}$} \\
\hline & Healthcare center & $11.30(1.30)$ & \\
\hline \multirow{2}{*}{ Place of birth } & City & $11.13(1.22)$ & \multirow{2}{*}{$\begin{array}{l}t=0.11 \\
P=0.9\end{array}$} \\
\hline & Village & $11.1(0.8)$ & \\
\hline \multirow{4}{*}{ Type of employment } & Permanent & 1.30))11.66 & \multirow{4}{*}{$\begin{array}{l}F=1.017 \\
P=0.4\end{array}$} \\
\hline & Fixed-term contract (5-year) & 1.02))11.04 & \\
\hline & Fixed-term contract (1-year) & 1.34))11.14 & \\
\hline & Daily paid & $1.7)) 11.75$ & \\
\hline \multirow{2}{*}{ Native language } & Persian & $11.14(1.2)$ & \multirow{2}{*}{$\begin{array}{l}t=0.32 \\
P=0.7\end{array}$} \\
\hline & Non-Persian & $11.07(1.14)$ & \\
\hline
\end{tabular}

Table 3. Correlation of Reproductive Behavior and Religious Orientation of Subjects

\begin{tabular}{lc}
\hline Variables & Mean $(\mathrm{SD})$ \\
\hline Reproductive behavior & $11.13(1.18)$ \\
Religious orientation & $77.7(10.87)$ \\
\hline
\end{tabular}

$\mathrm{R}=-0.23, P=0.01$

is subject to cultural and religious traditions, women's education and their participation rate as a labor force (30).

In this study, the mean (SD) age of marriage was 24.35 (4.32\%) years. The population-based study of Ranjbar et al revealed that the age of marriage and childbearing and the perceived spacing between the first and second child have been significantly increased in Iran in recent years (31). It was reported in another study that factors such as increased marriage age affect the reproductive behavior (32). A higher age at marriage shortens the duration of fertility period, thereby reducing the fertility rate $(33,34)$. In a study, Khan et al indicated that the childbearing is considerably dependent on the couples' age at the time of marriage, their education, the level of women's participation in the decision-making process, religiosity, and family income (35). In another study in Nepal, the following factors were among the most important variables affecting the reproductive variance: age at marriage, understanding of the ideal number of children, place of residence, literacy status, religion, exposure to media, use of family planning methods, the child death experience, and fertility (36).

The results of the study by Kieru et al, aimed at determining the factors affecting the reproductive behavior among low-income Kenyan women showed that income, education, occupation, attitude toward contraception, and religious orientation were significantly associated with the reproductive behavior (37). In another study, Rakibovna and Raphaelevich depicted that the housing problems and low wages reduced the fertility motivation. In contrast, factors including increased maternity benefits and receiving monthly fee for children up to one and a half years of age, and reduced taxation for the parents could increase the fertility motivation (38). In this study, a total of $78 \%$ of women used contraceptive methods and only a total of $21 \%$ of them had the desire to have children. Moreover, a total of $0.93 \%$ of women preferred to give birth to a daughter or expressed that the gender was not important.

In a study, Hezarjariby and Abbaspour reported that most of the educated women were employed and increased employment rate of women led to reduced fertility rate. The educated women devoted more time to study and were more familiar with contraceptive devices; as a result of which their fertility rate was reduced (39). Some studies have reported that the gender preference is inversely associated with the women's education $(1,40)$. In a study, Haldar et al indicated that gender preference depended on the religion, the literacy status, and place of residence (41). Moreover, in a study, Hosseini and Begi showed that the probability that working women show no tendency to childbearing was 1.39 times more than that in the unemployed women (42).

In a study, Sorush and Bohrani reported that there was a high convergence between women's educational level, ethnicity, age, gender attitudes, and different levels of religiosity (43). The findings of the study by Mahmudian and Shahriari displayed that the effect of residence, employment status, and education level on the women's reproductive behavior was influenced by the degree of development of their city of residence. However, religion had only significant effect on the severity of the impact of education level on the fertility rate (44). Asgari-Nedushan et al investigated the fertility ideals for working and nonworking Kurdish women. They showed that the fatalism in the reproductive behavior and the attitude toward the costs of child rearing had a significant effect on the fertility ideals of working and non-working women and that the average number of children of employed women was similar to that of unemployed women (45). In another study in Taiwan, it was reported that the female employment was less effective on their fertility 
rate (46). However, the results of the study by Sarukhani and Gudarzi, which was conducted to determine the effect of women's employment on the family, showed that the employment was associated with a reduction in the fertility rate and there was a negative correlation between the education level and the number of children in the families of working women (47). In a study by Adibi-Sadeh et al, the following variables made more contribution in explaining the reproductive behavior of Kurdish women resident in Andimeshk: education level, employment status of husband, and attitudes of individuals toward fertility (48). Thus, education is a strong indicator of a population's fertility changes (49).

\section{Conclusion}

Considering the meaningful relationship between the religious orientation and the reproductive behavior in this study, it seems that the fertility behavior would be significantly improved by strengthening the religious attitude of women. Moreover, it is recommended that more attention is paid to the issue of the spirituality and its associated factors in the society in order to promote the women's reproductive behavior by enhancing this component.

\section{Ethical Issues}

The ratification for the study was obtained from the Ethical Review Committee of the Research Deputy on Religion \& Health, Shahid Beheshti University of Medical Sciences, Tehran (Code Number: 8161).

\section{Conflict of Interests}

The authors declare no conflict of interests.

\section{Financial Support}

The Research Deputy on Religion \& Health of Shahid Beheshti University of Medical Sciences supported this study.

\section{Acknowledgments}

We would like to thank all who assisted us in this study. The authors thank the Research Deputy on Religion \& Health of Shahid Beheshti University of Medical Sciences for approving and financing this study.

\section{References}

1. Gholami A. The role of gender preference in reproductive behavior of women in the city of Kangavar (Persian). J Ilam Univ Med Sci. 2015;22(6):133-42.

2. Hosseinzadeh A, Entezari A, Ghazlavi A. Ethnicity and fertility (Persian). J Soc Dev. 2014;8(1):188-212.

3. Mahmoudi M. Demographic changes. The Challenges Ahead and Revising population policy; 2013. Persian.

4. Kalantari S, Abaszadeh M, Aminmozaffari F, Rakei Bonab N. Sociological Study tendency to childbearing and some related factors (Persian). Journal of Applicable Sociology 2011;21(37):83-104.

5. Abbasi-Shavazi MJ. Fertility revolution in Iran. Popul Soc. 2001;373:1-4.
6. Moshfeg M, Eshgi-gharib S. Analysis of the relationship between the value of children and fertility among women in Tehran. Women's Strategic Studies (Persian). 2012;15(58):12-94.

7. Momayez A, Gasemi A, Gasemi F. Factors contributing to the development of women entrepreneurship. Roshd-eFanavari. 2014;9(35):15-22. [Persian].

8. Magsudpur M. Factors affecting fertility decline in Iran from the perspective of economics in the period 1365-1390 Economic Journal. 2015;5,6:83-100.

9. Musaee M, Mehrgan M, Rezaee R. The fertility rate of women participation in the working (Case Study of the Middle East and North Africa). Women in Development Politics. 2011; 8(2):55-68.

10. Akintunde MO, Lawal MO, Simeon O. Religious roles in fertility behaviour among the residents of Akinyele Local Government, Oyo State, Nigeria. Int J Econ Manag Soc Sci. 2013;2(6):455-62.

11. Callister LC, Khalaf I. Spirituality in childbearing women. J Perinat Educ. 2010;19(2):16-24. doi: $10.1624 / 105812410 X 495514$.

12. Skirbekk V, Fukuda S, Hackett C, Stonawski M, Spoorenberg T, Muttarak R. Is Buddhism the low fertility religion of Asia? Demogr Res. 2015;32:1-28. doi: 10.4054/ DemRes.2015.32.1.

13. Moghadam SRM, Chegeni ME, Hafez AA. Explore the relationship among spiritual health, marital satisfaction, and demographic characteristics (age, duration of marriage, duration of employment) in Mafi hospital nurses of Susa city in 1394. Journal of Research on Religion \& Health. 2016;1(4):38-44.

14. Hatami H, Hobbi M, Akbari A. [The effect of religiosity on marriage satisfaction]. J Military Psychology (Persian). 2009;1(1):13-22.

15. Pearce LD, Brauner-Otto SR, Ji Y. Explaining religious differentials in family-size preference: Evidence from Nepal in 1996. Popul Stud (Camb). 2015;69(1):23-37. doi:10.1080 /00324728.2014.995695

16. Goldscheider C. Population, Modernization and Social Structure. Boston: Little, Brown; 1971.

17. Mahmudian $\mathrm{H}$, Nobakht R. Religion and fertility: reproductive behavior Sunni and Shia religious groups rancher turned in Fars province (Persian). Social Problems of Iran. 2007;1(1):198-215.

18. Hayford SR, Morgan SP. Religiosity and fertility in the United States: The role of fertility intentions. Social Forces. 2008;86(3):1163-88. doi:10.1353/sof.0.0000.

19. Peri-Rotem N. Religion and fertility in Western Europe: Trends across Cohorts in Britain, France and the Netherlands. Eur J Popul. 2016;32(2):231-65. doi:10.1007/ s10680-015-9371-z.

20. Pejhan A, Kamaliha A. The impact of cultural factors on fertility 49-15 years old District 12 of Tehran. Community Cultural Studies. Institute for Humanities and Cultural Studies. 2015;6(2):137-5.

21. Abassi-shovazi M, Mcdonald P, Hosseini-Chavoshi M, Kaveh-Firuz Z. The point of view of women in the reproductive behavior in Yazd province by using qualitative methods. J Soc Sci Lett. 2004;20:169-203.

22. Golriz G. Study of relationship between religious attitude with other feed back and job characterizations [B.Sc thesis] Tehran: Faculty of Literature and Human Sciences, Tehran University; 1974. [Persian]. 
23. Sadeghi M, Bagherzadeh Ladari R, Haghshenas M. A study of religious attitude and mental health in students of Mazandaran University of Medical Sciences (Persian). J Mazandaran Univ Med Sci. 2010;20(75):71-5.

24. Shiri T, Bidarian S. Economic factors affecting the reproductive population of women $15-49$ years old, working in Education District 22 of Tehran (Persian). J Soc Sci. 2009;3(3):94-107.

25. Hosseini G, Hosseini H. Compare the determinants of fertility behavior among women living in rural areas Rawansar and Gilan-e Gharb. J Med Univ Kermanshah (Persian). 2014;17(5):316-23.

26. Zhang L. Religious affiliation, religiosity, and male and female fertility. Demogr Res. 2008;18(8):233-62.

27. Westoff CF, Bietsch K, Lopez L, et al. Religion and reproductive behavior in sub-Saharan Africa. Cochrane Database Syst Rev. 2015;6(2):CD003036.

28. Morgan SP, Stash S, Smith HL, Mason KO. Muslim and non-Muslim differences in female autonomy and fertility: evidence from four Asian countries. Popul Dev Rev. 2002;28(3):515-37.

29. Lund EM. Be Ye Fruitful and Multiply: Does Religious Activation Increase Reproductive Desire? [Thesis] Lexington, Kentucky: University of Kentucky; 2014.

30. Atif M, Janjua IM, Arfan Riasat D, Akhtar S, Riasat G. The effect of socio-economic and demographic factors on fertility behaviour in Faisalabad (Pakistan). Global Journal Of Human Social Science Sociology, Economics \& Political Science. 2012;12(13-C).

31. Ranjbar F, Shirzad M, Kamali K, et al. Fertility behaviour of Iranian women: A community-based, cross-sectional study. Arch Iran Med. 2015;18(1):2-5.

32. Nahar MZ, Zahangir MS, Shafiqul Islam S. Age at first marriage and its relation to fertility in Bangladesh. Chinese Journal of Population Resources and Environment. 2013;11(3):227-35. doi:10.1080/10042857.2013.835539.

33. Solnake BL. Marriage age, fertility behavior, and women's empowerment in Nigeria. Sage Open. 2015;5(4). doi: $10.1177 / 2158244015617989$.

34. Chaudhury RH. The influence of female education, labor force participation, and age at marriage on fertility behavior in Bangladesh. Soc Biol 1984;31(1-2):59-74. doi:10.1080/19 485565.1984.9988562.

35. Khan MM, Zafar MI, Ali T, Ahmad A. Effect of socioeconomic, cultural and demographic factors on woman reproductive health. Pak J Agric Sci. 2009;46:4:308-14.

36. Adhikari R. Demographic, socio-economic, and cultural factors affecting fertility differentials in Nepal. BMC
Pregnancy Childbirth. 2010;10:19. doi:10.1186/1471-239310-19.

37. Kieru JN, Ngige LW, Ondigi AN. Factors associated with reproductive behavior of low income mothers in Kiandutu slum in Thika Municipality, Kenya. Asian Soc Sci. 2015;11(24):350-6.

38. Rakibovna KY, Raphaelevich KR. Social factors and features of the reproductive behaviour of the population of the Republic of Tatarstan. Procedia Economics Financ. 2015;24:533-6. doi:10.1016/S2212-5671(15)00625-5.

39. Hezarjariby J, Abbaspour A. The effect of social-economic factors on women's fertility. Soc Res. 2010;3(6):139-53.

40. Leone T, Matthews Z, Zuanna GD. Impact and determinants of sex preference in Nepal. Int Fam Plan Perspect. 2003:29(2):69-75. doi:10.2307/3181060.

41. Haldar A, Dasgupta U, Sen S, Laskar K. Influence of social correlates on gender preference and small family norm: an impression from West Bengal. J Fam Welfare. 2011;57(1):79-84.

42. Hosseini H, Begi B. Determinant of economic, social, cultural and demographic trends childbearing women married referred to health centers in Hamadan (Persian). J Kermanshah Univ Med Sci. 2015;18(1):35-43. Persian

43. Sorush M, Bohrani S. The relationship between religiosity, attitudes to gender roles and attitudes to children, with the actual and ideal number of children (Persian). J Women Dev Polit. 2014;11(2):189-208.

44. Mahmudiani S, Shahriari S. The role of religion in the development of the reproductive behavior of kord women in Iran (Persian). J Kurdistan Univ Med Sci. 2015;20:91100.

45. Asgari-nedushan A, Hosseini H, Karimi H. A comparative study of the determinants of fertility ideals the employed and unemployed women in Sanandaj. Women's Strategic Studies. 2015;17(67):45-83.

46. Stokes CS, Hsieh YS. Female employment and reproductive behavior in Taiwan, 1980. Demography. 1983;20(3):313-31.

47. Sarukhani B, Gudarzi B. Women's employment effects on families (Persian). Journal of Contemporary Sociology. 2010;2(1):51-78.

48. Adibi-Sadeh M, Sieiahpush E, Darvishzadeh Z. The amount of increased fertility and the factors affecting it among the tribes living in Andimesh (Persian). J Iran Soc Dev Stud. 2012;4(1):81-98.

49. Nag A, Singhal P. Impact of education and age at marriage on fertility among Uttar Pradesh migrants of Ludhiana, Punjab, India. Anthropologist. 2013;15(2):225-30.

Copyright $\odot 2017$ The Author (s); This is an open-access article distributed under the terms of the Creative Commons Attribution License (http://creativecommons.org/licenses/by/4.0), which permits unrestricted use, distribution, and reproduction in any medium, provided the original work is properly cited. 